\title{
O JOGO COMO CONTEÚDO NO CURRÍCULO DE CURSOS DE EDUCAÇÃO FÍSICA - LICENCIATURA
}

\author{
Marluce Raquel Decian \\ Universidade Federal de Pelotas, Rio Grande do Sul, Brasil. \\ Andressa Aita Ivo \\ Universidade Federal de Santa Maria, Rio Grande do Sul, Brasil. \\ Elizara Carolina Marin \\ Universidade Federal de Santa Maria, Rio Grande do Sul, Brasil.
}

\begin{abstract}
Resumo
Este estudo tem o objetivo de compreender o jogo como conteúdo da Educação Física no Ensino Superior, a partir da análise dos currículos das Universidades Federais do Rio Grande do Sul e da atuação dos docentes responsáveis pelas disciplinas que contemplam tal conteúdo. Para alcançarmos esse propósito, lançamos mão da análise documental e de entrevistas semiestruturadas. Os achados evidenciam que o conteúdo jogo é predominantemente contemplado por uma disciplina obrigatória, ofertada nos primeiros semestres, todavia nem sempre como objeto central. Observamos, ainda, o distanciamento entre o que propõe o Projeto Pedagógico de Curso e o que se materializa nos currículos, a sobreposição de determinadas áreas de conhecimento e o direcionamento do conteúdo jogo ao universo infantil.
\end{abstract}

Palavras-chave: Educação Física. Currículo. Jogo.

\section{Introdução}

As discussões sobre currículo e formação inicial têm assumido importância crescente nas políticas educacionais e na formação de professores. Trata-se de uma arena de disputas e de relações de poder, cuja razão é a de definir qual conhecimento e quais práticas devem prevalecer no processo educacional.

A partir das teorias críticas (APPLE, 1982; GIROUX, 1986; SANTOMÉ, 1995), o currículo é visto como um espaço de poder, ao qual uma série de características sociais e políticas são incorporadas. Nessa esteira, para Silva (2006), cultura e currículo são, antes, relações sociais, e o currículo como relação social pode ser percebido por intermédio de suas marcas, advindas de disputas por predomínio cultural, das lutas entre, de um lado, os saberes oficiais, dominantes, e, de outro, os saberes subordinados, desprezados. Assim, o currículo se constitui por meio de relações sociais que, necessariamente, são relações de poder e, por isso, determinam quais os conhecimentos considerados socialmente válidos.

Por formação inicial entendemos o percurso dos estudos especializados, que se dá até a conclusão do curso superior e habilita o profissional para atuar em uma determinada área. Salgado (2000) considera a formação inicial de professores a primeira etapa de um processo de construção de saberes, acoplado à experiência pedagógica dos futuros professores e ao currículo disciplinar, dentro de uma instituição de ensino superior, que mais tarde se 
complementa e amplia por meio da formação continuada, mas que contribui e influencia sobremaneira o exercício da função.

Sob o entendimento de Educação Física como uma prática pedagógica, que trata da cultura corporal historicamente construída pela humanidade - tal como o jogo, o esporte, a dança, a ginástica (COLETIVO DE AUTORES, 2012), e que, portanto, demandam ser conhecidas e reelaborados pelos sujeitos - é que buscamos compreender o jogo como conteúdo da Educação Física (EF) no Ensino Superior, a partir da análise dos currículos das Universidades Federais do Rio Grande do Sul e da atuação dos docentes responsáveis pelas disciplinas que contemplam tal conteúdo.

O foco no conteúdo jogo advém do contexto das pesquisas que temos realizado e da amplitude do seu significado, que, segundo Elkonin (1998, p.19), envolve várias experiências, realizadas desde a infância até a vida adulta "em que se reconstroem, sem fins utilitários diretos, as relações sociais". Para o autor, as pessoas jogam de acordo com aquilo que vivem em seu cotidiano, ou seja, conforme suas condições de vida e de trabalho. Por meio do jogo é possível compreender tanto o universo lúdico quanto a organização social dos grupos humanos nos diferentes tempos e espaços.

O jogo é considerado um elemento universal de toda a cultura humana. Pesquisadores de diferentes áreas, países e períodos históricos têm dedicado importância ao tema. Alguns são considerados clássicos no assunto, a exemplo do filósofo holandês Johan Huizinga (18721945), autor da obra "Homo Ludens: o jogo como elemento da cultura" (1938; 1971; 1980); do sociólogo francês Roger Caillois (1913-1978), que escreveu "Os Jogos e os Homens: a máscara e a vertigem" (1958; 1990); do psicólogo ucraniano Daniel Elkonin (1904-1984), autor da obra "Psicologia do Jogo" (1978; 1998); da pedagoga brasileira Tizuko Morchida Kishimoto, cuja obra "O jogo e a educação infantil" (1994) tem sido referência no trato do tema; dentre outros.

\section{Encaminhamentos teórico-metodológicos}

Para atender às demandas da investigação, lançamos mão da pesquisa documental que, na perspectiva de May (2004), facilita a compreensão do contexto. Delimitamos como objetos para análise o Projeto Pedagógico dos Cursos (PPC) de Educação Física - Licenciatura, a matriz curricular e os programas das disciplinas. Os documentos foram coletados nos sites e diretamente nas coordenações dos cursos das cinco universidades públicas federais do RS que oferecem o Curso de Educação Física, habilitação em Licenciatura, quais sejam: Universidade Federal de Pelotas (UFPel), Universidade Federal do Rio Grande do Sul (UFRGS), Universidade Federal de Santa Maria (UFSM), Universidade Federal do Rio Grande (FURG) e Universidade Federal do Pampa (UNIPAMPA), Campus Uruguaiana. A coleta dos dados ocorreu no período de julho a agosto de 2013.

Também foram realizadas entrevistas semiestruturadas de acordo com Triviños (1987) com os professores das Instituições de Ensino Superior investigadas, responsáveis pelas disciplinas que contemplam em seus programas o conteúdo jogo e analisadas à luz dos pressupostos de Bardin (2011). Totalizaram seis docentes: um professor substituto e cinco efetivos, com dedicação exclusiva e com tempo de magistério que varia entre 17 e $30 \operatorname{anos}^{24}$. 


\section{O Conteúdo “Jogo" no âmbito da Formação Inicial em Educação Física - Licenciatura de Universidades Federais}

Apesar de o PPC ser um documento que apresenta princípios norteadores para os cursos, no qual são traçadas ações para o ensino, pesquisa e extensão, cada PPC tem suas próprias particularidades, as quais estão diretamente ligadas ao grupo de docentes que contribuiu na sua elaboração, à formação dos docentes, à legislação e às políticas públicas para o Ensino Superior.

A análise particular do PPC e da matriz curricular dos Cursos de EF das cinco Universidades Federais do Rio Grande do Sul proporcionou um panorama sobre a estrutura, a organização, o currículo e a formação pretendida por cada Instituição, enquanto que a análise dos programas das disciplinas possibilitou compreender mais detalhadamente as peculiaridades das disciplinas e a relação com o conteúdo jogo.

O PPC do curso de EF da Universidade A articula as Unidades do Conhecimento de formações específica e ampliada, sustentadas em seis dimensões que regem a estrutura e a organização curricular do curso. Tais dimensões aparecem agrupadas nas seguintes Unidades de Conhecimento: Relação Ser Humano-Sociedade; Biológica do Corpo Humano; Produção do Conhecimento; Culturais do Movimento Humano; Técnico-Instrumental; DidáticoPedagógica ${ }^{25}$.

Foi possível verificar que, das 2.520 horas de disciplinas obrigatórias do curso, $32,74 \%$ fazem parte da Unidade de Conhecimento "Técnico-Instrumental", enquanto que $17,26 \%$ das horas são destinadas à unidade "Culturais do Movimento Humano", que contempla, entre outras disciplinas, "Ludicidade e Educação Física" e "Estudos do Lazer", ambas com 60 horas, ofertadas respectivamente no $1^{\circ}$ e $4^{\circ}$ semestres e com sistematização teóricoprática.

O programa da disciplina Ludicidade e Educação Física está organizado em cinco unidades e enfoca o jogo nos diferentes níveis de ensino da Educação Básica. Busca oportunizar aos acadêmicos vivências, leituras e reflexões para o trabalho com esse conteúdo na Educação Básica. Na bibliografia referenciada há autores tais como Huizinga (1980) e Volpato (2002), que tecem discussões filosóficas e sociológicas sobre o jogo, bem como Faria Junior (1996), que defende a importância dos jogos populares na Educação Física Escolar.

$\mathrm{Na}$ disciplina "Estudos do Lazer", o jogo aparece como conteúdo com caráter pedagógico capaz de ser adotado no âmbito das Políticas Públicas de Lazer e da Educação Física Escolar. Relaciona como referência específica do tema o capítulo "Jogos e Brincadeiras", da obra de Rangel e Darido (2005), cuja ênfase é discutir e propor orientações pedagógicas para atuação docente com o jogo.

A matriz curricular do curso de EF da Universidade B é organizada por eixos curriculares, articulados por diferentes componentes curriculares, procurando contemplar uma formação generalista e ampla acerca dos diversos conteúdos que compõem o campo do saber da Educação Física, denominados de: "Biodinâmico", "Cultura do Movimento", "TécnicoCientífico", "Bases Socioculturais e Pedagógicas" e "Formação Docente". Totalizam 2.730 horas obrigatórias.

25 Cabe esclarecer que do total de horas destinadas a essa Unidade de Conhecimento, 400 são destinadas aos Estágios Curriculares Supervisionados, conforme previsto no Parecer n. ${ }^{\circ} 28 \mathrm{CNE} / \mathrm{CP} / 2001$. 
De acordo com o PPC, as dimensões pedagógicas na formação do licenciado estão presentes ao longo de todos os eixos curriculares, sendo enfatizadas nos seguintes: "Bases Socioculturais e Pedagógicas" e "Formação Docente". Contudo, a análise da matriz curricular evidencia alto percentual de disciplinas de cunho biológico, em contraposição à própria formação prevista pelo PPC (2012, p.21), que pretende propiciar uma formação com orientação inerente "para a atividade docente, que prepare para o ensino visando à aprendizagem do aluno; o exercício de atividades de enriquecimento cultural; o aprimoramento em práticas investigativas (...)".

As propostas do PPC, quando se materializam no currículo do curso, apontam um distanciamento entre o que se pretende e o que se efetiva na organização curricular. Em análise sobre o currículo, a partir das teorias críticas, Silva (2006) sustenta que o currículo é entendido como uma construção social, ou, ainda, uma invenção social como tantas outras. Em certo momento, a partir de processos de disputa e conflito social, determinadas estruturas curriculares se tornaram consolidadas como o currículo, que é, portanto, resultado de um processo histórico.

Esse mesmo critério pode ser observado no que tange ao conteúdo jogo; conforme o conteúdo programático das disciplinas foi possível identificá-lo apenas na disciplina intitulada "Educação Física e Infância", com carga horária de 30 horas, localizada no eixo curricular "Bases Socioculturais e Pedagógicas", ofertada no $4^{\circ}$ semestre e com sistematização teóricoprática. Embora na ementa da disciplina apareça o conteúdo jogo, no programa da disciplina fica evidente que o conteúdo central é infância, uma vez que a disciplina tem como objetivo "desenvolver científica e pedagogicamente acerca da concepção de infância que as instituições de ensino assumem e que vem sendo incorporada pela educação física escolar" (PPC, 2012, p.91). O jogo se apresenta como um dos conteúdos a serem tratados na disciplina.

Dentre as referências bibliográficas básicas sugeridas para essa disciplina, encontramos a obra "Reflexões: a criança, o brinquedo, a educação", de Walter Benjamin, que tece reflexões sobre os efeitos do capitalismo e da industrialização nas brincadeiras das crianças, nas relações entre as crianças e os adultos, nos materiais utilizados para confeccionar os brinquedos, entre outros.

É inegável a importância do jogo, do brinquedo e do lúdico no período da infância, como propõe a disciplina. Contudo, cabe destacar que se trata de uma dimensão da vida humana que pode compor todas as fases, não restringindo sua vivência apenas à infância ou aos primeiros anos da escolarização. Vários autores (ELKONIN, 1998; HUIZINGA, 1980; CAILLOIS, 1990) defendem o jogo como manifestação cultural, portanto, presente em todas as idades.

O curso de EF da Universidade C organiza o seu currículo em três Eixos de Formação, os quais articulam as unidades de conhecimento de formação específica e ampliada conforme a Resolução CNE/CES 7/2004. Tal organização tem por finalidade possibilitar a aquisição de habilidades que favoreçam o desenvolvimento das diferentes competências, referentes à qualificada atuação do licenciado em Educação Física. Desse modo, esses três Eixos de Formação são compostos por diferentes núcleos de conhecimento que, por sua vez, são constituídos por diferentes disciplinas.

$\mathrm{Na}$ matriz curricular do Curso foram identificadas duas disciplinas, denominadas "Dinamização de Programas em Lazer e Recreação" e "Fundamentos da Educação Física na Educação Infantil", que contemplam o conteúdo jogo em seus programas. A primeira, ofertada no $3^{\circ}$ semestre, com carga horária de 60 horas, propõe-se a desenvolver a compreensão e a 
fundamentação teórico-prática do acadêmico para caracterizar, organizar e planejar atividades recreativas, jogos e lazer, ressaltando os valores e implicações pedagógicas nos diversos campos de sua atuação profissional. Nas referências bibliográficas indicadas não encontramos obras que tratem especificamente do conteúdo jogo. Podemos inferir, nesse sentido, que nessa disciplina o jogo tem um caráter essencialmente prático, sem aprofundamento teórico; muito provavelmente, em função de o jogo ser largamente utilizado no processo educativo como recurso didático-pedagógico para o ensino de outro conteúdo. Maschio e Ribas (2009) alertam que os jogos vêm se constituindo como meio de iniciação ao esporte, como recreação ou relaxamento, e não como um conteúdo escolar; e ainda sendo utilizado nos anos iniciais do ensino fundamental e raramente nos anos finais e ensino médio. Cabe destacar, conforme o estudo realizado por Decian e Marin (2011) sobre os Referenciais Curriculares para o Ensino Médio de diferentes estados brasileiros, que, normalmente, o conteúdo jogo é proposto apenas para os primeiros anos do Ensino Fundamental e com um percentual quantitativo reduzido, sendo que para o Ensino Médio ele sequer é mencionado. Fica evidente que o conhecimento sobre jogo tanto no Ensino Fundamental quanto no Ensino Médio é negado.

A disciplina "Fundamentos da Educação Física na Educação Infantil", ofertada no $4^{\circ}$ semestre, com carga horária de 45 horas, aborda o ensino das habilidades motoras fundamentais, jogos, atividades rítmicas e ginástica no contexto da educação infantil. A partir do programa da disciplina, observamos que são reservados dois encontros dessa disciplina para o conteúdo jogo. Assim como acontece na Universidade B, o conteúdo jogo na Universidade C é destinado ao trabalho desenvolvido na Educação Infantil, expresso na própria nomenclatura da disciplina.

O PPC do Curso de EF da Universidade D organiza-se a partir da relação de disciplinas obrigatórias e optativas. Conforme Bernstein (1996), trata-se de um modelo curricular linear-disciplinar, estruturado a partir de um conjunto de disciplinas justapostas, de modo geral, de uma forma bastante arbitrária.

A análise da matriz curricular evidencia privilégio de disciplinas de cunho técnico e biológico, contrapondo-se ao que prevê o próprio PPC (2010, p.17), quando define como meta principal a formação de "professores da Educação Básica (...), capazes de desenvolver, crítica e pedagogicamente, atividades de ensino (...) através, principalmente, do esporte, da dança, da ginástica e da recreação a nível escolar".

No que tange especificamente ao conteúdo jogo, observamos que este é contemplado apenas na disciplina "Atividades Lúdicas na Escola", com carga horária total de 51 horas e ofertada no $1^{\circ}$ semestre. Tal disciplina tem por objetivo a sistematização de conhecimentos e vivência de experiências no âmbito das práticas sociais, na esfera do jogo, em suas dimensões lúdicas e esportivas, de maneira a permitir que o futuro licenciado construa aptidões necessárias para atuar nos contextos social e escolar, com vistas a sua transformação.

Dentre as bibliografias básicas sugeridas para essa disciplina, há obras de caráter instrumental, ou seja, que dão suporte metodológico para o ensino dos jogos (a exemplo de ALBERTI \& ROTHENBERG, 1984; DIETRICH; DÜRRWACHTER \& SCHALLER, 1984) e também obras de caráter filosófico e sociológico, tais como as de Huizinga e de Caillois.

O currículo do curso de EF da Universidade E é estruturado de modo semelhante ao da Universidade D, com a listagem de disciplinas obrigatórias e optativas, tendo 2.520 horas obrigatórias. Além da formação geral, constituída a partir das diferentes abordagens da filosofia, da sociologia, da psicologia, da antropologia, da ecologia e da biologia, o curso propõe tratamento equânime às diferentes manifestações da cultura corporal - jogos, ginásticas, esportes, lutas e danças, visando à sólida formação pedagógica. 
De modo particular, o PPC é organizado a partir dos temas da cultura corporal, sendo "a corporeidade e o movimento humano [...] elementos centrais na problematização e convergência das disciplinas, que têm como objetivo a formação do professor de Educação Física, qualificando-o para a atuação docente" (PPC, 2005, p.10). Assume a perspectiva de que o currículo não deve "privilegiar nenhum dos temas da cultura corporal em particular, atribuindo a todos a mesma perspectiva de análise e aprofundamento" (PPC, 2005, p.11).

Entretanto, os dados mostram que a disciplina intitulada "Jogos" é a única que contempla o conteúdo no currículo do curso. Trata-se de uma disciplina de caráter teóricoprático, obrigatória, com carga horária de 60 horas, ofertada no $4^{\circ}$ semestre. Tem como objetivo análise e problematização dos jogos como manifestação corporal constituída historicamente, além de vivências e estudo da caracterização dos jogos, dos respectivos contextos históricos e dos processos de vinculação entre o jogo e a educação.

Em relação às bibliografias que embasam essa disciplina, encontramos os clássicos, como Huizinga, Caillois e Kishimoto. Ainda que o jogo apareça como conteúdo central, ao ser contemplado em apenas uma disciplina inviabiliza o contato do aluno e o aprofundamento do conteúdo ao longo do processo de formação inicial.

A construção de um currículo orientado pelos temas da cultura corporal, embora represente um avanço para a área, quando se materializa, ainda assim relega temas da própria cultura corporal, como acontece com o conteúdo jogo na formação inicial.

\section{O conteúdo jogo a partir da concepção dos professores que ministram disciplinas que contemplam a temática}

O diálogo que segue vai na direção de sinalizar para as experiências dos docentes das cinco universidades do Rio Grande do Sul que atuam com o conteúdo jogo no que tange: às contribuições para a formulação do PPC e o programa da disciplina; às ações que visibilizam a relevância do conteúdo; às condições reais e objetivas de trabalho.

Identificamos que dois dos docentes entrevistados não participaram do processo de construção do PPC da instituição. Os que participaram relatam que a sua participação foi decisiva para dar visibilidade e conquistar a inclusão do jogo como temática via disciplinas específicas ou relativas e em que o jogo é abordado. No caso da Universidade C, o Prof. ${ }^{o}$ João destaca que o Currículo estava "restrito a uma disciplina de Recreação. Hoje temos 3 disciplinas que o contemplam (...) em diferentes semestres ao longo do curso". Portanto, para três universidades a participação efetiva dos professores na elaboração do PPC garantiu a inclusão de disciplinas na matriz curricular do curso.

Na perspectiva dos docentes, a fundamentação da argumentação se deu na direção de realçar o jogo como um conteúdo que se "contrapõe à hegemonia histórica da $E F$, (...) que faz parte da cultura historicamente produzida pela humanidade. E faz elo com aquilo que é

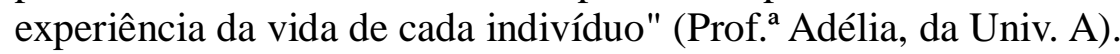

Os professores fazem coro a autores como Melo (1997), Neira (2009) e Soares et al. (1992), que, por diferentes abordagens, têm demonstrado que o jogo, para além de uma alternativa pedagógica, precisa ser entendido, apreendido, refletido e reconstruído enquanto conhecimento que constitui o acervo cultural da humanidade, possibilitando sua constatação, sistematização, ampliação e aprofundamento.

Quanto ao trabalho pedagógico, os professores entrevistados foram unânimes em realçar que o trato do conteúdo jogo demanda articulação entre teoria e prática, ou seja, demanda o desenvolvimento de uma "práxis". Conforme sustenta Frigotto (2008), a unidade 
indissolúvel de duas dimensões no processo do conhecimento, a teoria e a ação, expressa-se na práxis. Na perspectiva de Frizzo (2008, p. 163), "uma teoria é válida à medida que transforma a prática, e a prática também é verdadeira à medida que transforma a teoria". No entanto, identificamos que as estratégias pedagógicas e a organização da carga horária nem sempre garante a "práxis":

(...) a minha preocupação então sempre é reflexão e vivência, como isso dialoga, em geral eu organizo as minhas aulas metade/metade, metade

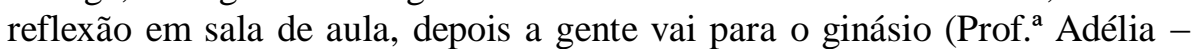
Univ. A).

(...) os alunos precisam, não só de teorias sobre educação física infantil, mas vivenciar quais as atividades, o porquê das atividades, por que jogar, por que brincar (Prof. a Paula - Univ. C).

(...) teórico-prático, de modo que nessa disciplina eu dou mais ênfase na vivência do que na teoria, porque no tripé como a gente pensou primeiro vivencia, reflete e depois aplica, então nessa vivência, nessa linha que eu trabalho, $70 \%$ da disciplina é vivência (Prof. João - Univ. C).

A própria carga horária das disciplinas (variam entre 30 e 60 horas) torna-se um obstáculo para o trabalho dos professores, impelindo a sistematização dos conteúdos de forma acelerada e superficial, como explicitam as seguintes falas:

Atualmente, com a redução da carga horária, está faltando uma parte que eu acho extremamente importante que é o contato dos alunos com as crianças (...) e aprofundamento de questões conceituais. Precisaria de uma carga horária mais elevada, porque fica superficial (Prof. ${ }^{a}$ Paula - Univ. C).

Eu acredito que tinha que ter uma parte prática, a disciplina é extremamente teórica, são 30 horas de somente teoria (...) então a gente está tentando achar algum espaço para dar essa vivência do jogo em si, nessa disciplina (Prof. ${ }^{a}$ Mariza - Univ. B).

No que se refere às condições de infraestrutura para a realização do trabalho pedagógico com o jogo, identificamos três concepções distintas. Uma que sinaliza para a diversidade de espaços e materiais, conquistados com facilidade, como destaca Prof a a Mariza (Univ. B), em virtude de ser um curso novo e com proposta fundamentada na perspectiva da cultura corporal:

(...) tem bastante material, materiais variados, não só bola, redes, nós temos cones, bambolês, nós temos muitos materiais até como eu disse a universidade é nova, estão adquirindo muita coisa e o material ainda está intacto, não está sucateado nem nada, então dá para a gente utilizar bastante material nas aulas.

Outra, como no caso da Prof. ${ }^{a}$ Ana (Univ. E) e do Prof. João (Univ. C), que expõem não haver grande preocupação com espaços e materiais, pois procuram tratar o conteúdo estabelecendo relação com as condições disponíveis na atuação no âmbito escolar. 
(...) eu costumo dizer assim para eles: tem que estar preparado para trabalhar simplesmente com as classes que tu tem em sala de aula e podem fazer inúmeras brincadeiras e atividades, então materiais que eu poderia fazer outras atividades, tendo outros materiais com certeza eu faria, mas eu não as faço pelo fato de que, que me adianta proporcionar aos meus alunos uma experiência e quando eles chegarem em seu campo de atuação, eles não têm aquela estrutura ou material que eu propus (Prof. o João - Univ. C).

A aproximação da Formação Inicial com a realidade do contexto escolar é de suma importância para a formação de professores. Contudo, a prática pedagógica dos professores não pode ficar restrita a essa realidade, mas deve possibilitar o maior repertório possível de conhecimentos para os professores em formação, com vistas a superar os desafios postos pelo cotidiano escolar. O que se coloca é a demanda permanente da crítica das condições materiais do ensino e de oferecer aos graduandos subsídios para "compreenderem os contextos históricos, sociais, culturais, organizacionais e de si mesmos como profissionais, nos quais se dá sua atividade docente, para neles intervir, transformando-os", como assinala Pimenta (2002, p.26).

E, por fim, uma terceira concepção, como sinaliza a Prof. ${ }^{a}$ Adélia, ao relatar as dificuldades que teve dentro da instituição, para garantir condições de trabalho adequadas no que se refere a espaços, aquisição de materiais e reconhecimento do conteúdo. Eis o relato sobre essa experiência:

Meu processo, para conseguir espaços (...), foi um processo de conquista, de luta, de força, que travei até conseguir. Em termos de materiais, tem sido também um processo de conquista, de busca. Com a burocracia das universidades, nem sempre é possível comprar os materiais, especialmente relacionados ao lúdico, ao jogo. Se você solicita ao almoxarifado, ou via licitação, para os esportes, por exemplo, você encontra. Para o jogo você não encontra. Sempre tem dificuldade de aquisição desses materiais. Tenho insistido nas diferentes gestões pelos quais passou o Centro e elaborado projetos. Assim eu garanto a compra de materiais ou confecção (Prof. ${ }^{a}$ Adélia - Univ. A).

O relato da docente evidencia a luta por espaço dentro da instituição de ensino, por aquisição de materiais e esforço para dar visibilidade às disciplinas que ministra. Luta realimentada a cada gestão administrativa e aos entraves dos modos de funcionamento das Universidades, que muito mais contribuem para reproduzir a hegemonia de determinados conhecimentos. Na esteira de Veiga (2010), a docência requer autonomia e consciência crítica para analisar o processo educativo, a conjuntura social mais abrangente, a função social do trabalho do professor, as finalidades educativas pretendidas e sua concretização. A autora pontua a docência como uma atividade teórico-prática, que pressupõe incontestavelmente o vínculo indissociável da unidade entre teoria e prática, entre finalidade e ação, entre o saber e o fazer, entre concepção e execução, ou seja, trabalho constante de análise e crítica, de atividade criativa, de superação e de proposta de ação, inclusive entre o professor, o aluno e o contexto social em que está situada a instituição de Educação Superior.

Quanto aos pressupostos teóricos, à análise dos programas das disciplinas e das entrevistas dos professores permitiu constatar a presença de autores clássicos e de noções 
importantes que contribuem para enunciar elementos fundamentais para as reflexões sobre o conteúdo jogo.

\section{Considerações Finais}

Os currículos refletem coexistência de teorias e concepções, constituindo um território de lutas interdisciplinares, quer pelas diferentes abordagens epistemológicas, quer pelos conteúdos tratados (biológicos, psicológicos ou culturais). A partir da análise do PPC e da matriz curricular dos cursos investigados, identificamos que o conteúdo jogo é predominantemente contemplado por apenas uma disciplina obrigatória, com carga horária que varia entre 30 e 60 horas, ofertada nos primeiros semestres, nem sempre, todavia, como objeto central.

A complexidade do tema, a diversidade de teorias e abordagens e a importância da vivência evidencia que a carga horária destinada é extremamente pequena, sobretudo naquelas com apenas 30 horas. Se pensarmos, à luz do que expõem Michelotti e Souza (2008), que a estruturação dos currículos dos cursos de licenciatura e a materialização da Educação Física como disciplina curricular escolar estão ligadas de forma dialética, o conhecimento do conteúdo jogo (como o de outros) foi e está sendo negado no processo educacional das gerações contemporâneas.

Como adverte Lavega Burgués et al. (2011), discutir jogos no momento atual expressa um desafio para profissionais e pesquisadores, uma vez que as práticas corporais, no decorrer da história, com o surgimento da racionalização e da produtividade, tornaram a perspectiva biológica e esportivizante como sendo o hegemônico, tratando-o como forma determinante e central da dimensão da cultura corporal.

Observamos a atribuição do jogo como reduto da infância e associado à capacidade de desenvolver comportamentos cognitivos, afetivos, sociais e motores, visando a determinadas aprendizagens, o desenvolvimento infantil e como meio de educação escolar da criança. Mas também abordagem filosófica, sociológica, cultural e histórica mediadas por autores e obras clássicas, para além da instrumentalização técnica.

A abordagem dos conteúdos sob os vieses cultural e social insere o jogo numa conjuntura de práticas sociais e corporais que envolvem questões de classe, de poder, de tradição, ou seja, numa conjuntura que expressa tanto violência, conformismo e desigualdades quanto educação, resistência e solidariedade. Tal como lembra Nogueira (2007, p.131), tratar o jogo como uma produção cultural envolve ir além da compreensão dos determinantes biológicos, do aperfeiçoamento da técnica esportiva, do desenvolvimento intelectual e da aptidão física, de recurso pedagógico facilitador da aprendizagem, de alternativa para dias de chuva. Em suma, tratar o jogo como uma produção cultural demanda "compreendê-lo como uma manifestação contraditória constituída na complexidade que envolve a vida social e marcada tanto por situações de injustiça e desigualdade, como por possibilidades e utopias".

Sem dúvida, há muito trabalho a ser feito para que o conteúdo jogo legitime a sua intervenção no bojo da formação inicial em Educação Física. Contudo, identificamos no contexto dos cursos analisados sinais de conquistas e de luta. Mas para que o conteúdo jogo seja apropriado na Educação Física, demanda tanto ser contemplado nos PPP quanto ser concebido de modo abrangente e aprofundado para promover, na formação inicial, um aprendizado fecundo e experiências que possam se consubstanciar no trabalho pedagógico escolar. Demanda, em síntese, comprometimento do professor universitário com a participação na gestão dos PPP e dos currículos, com o conhecimento sobre as abordagens 
teórico-metodológicas, com a construção de uma base teórica sólida em torno dos conteúdos disciplinares, com a conquista de espaço e materiais e com uma ação crítica e criativa.

\title{
THE GAME AS CONTENT IN THE CURRICULUM OF UNDERGRADUATE PHYSICAL EDUCATION COURSES
}

\begin{abstract}
This study had the objective to understand the game as content in Physical Education in higher education, based on the analysis of the curriculums of the Federal Universities of Rio Grande do Sul, as well as to understand the behavior of the professors that are responsible for the courses that include this content. To achieve this purpose, we employed documental analysis and semi-structured interviews. The findings show that the game content is predominantly contemplated by a mandatory class, offered during the first semesters, however not always as a central subject. We also observed the distance between what the Educational Projects (PPC in Portuguese) propose and what occurs in the curriculums; certain areas of knowledge are given priority and game content is considered part of the world of children.
\end{abstract}

Key-words: Physical Education. Curriculum. Game.

\section{EL JUEGO COMO CONTENIDO EN EL CURRÍCULO DE CURSOS DE EDUCACIÓN FÍSICA-LICENCIATURA}

Resumen: Este estudio tuvo el objetivo de comprender el juego como contenido de la Educación Física en la educación superior, a partir del análisis de los currículos de las Universidades Federales de Rio Grande do Sul y de la actuación de los profesores responsables por las clases que contemplan tal contenido. Para alcanzar tal propósito, se empleó el análisis documental y entrevistas semiestructuradas. Los hallazgos evidencian que el contenido del juego es predominantemente contemplado por una clase obligatoria, ofrecida en los primeros semestres, sin embargo no como un objeto central. También observamos el distanciamiento entre lo que propone el Proyecto Pedagógico del Curso (PPC) y lo que se materializa en los currículos, la sobreposición de determinadas áreas de conocimiento y el direccionamiento del contenido del juego al universo infantil.

Palabras-claves: Educación Física. Currículo. Juego.

\section{Referências}

ALBERTI. H.; ROTHENBERG, L. Ensino de jogos esportivos. (tradução de Elisabeth Anneri Silveira). Rio de Janeiro: Ao livro Técnico, 1984.

APPLE, Michel. Ideologia e currículo. (tradução de Carlos Eduardo Ferreira de Carvalho). São Paulo: Brasiliense, 1982.

BARDIN, Laurence. Análise de conteúdo. São Paulo: Edições 70, 2011.

BERNSTEIN, B. A estruturação do discurso pedagógico: classe, códigos e controle. Petrópolis, RJ: Vozes, 1996.

BRASIL. Conselho Nacional de Educação. Parecer CNE/CES 058/2004, de 18 de fevereiro de 2004. Institui as Diretrizes Curriculares Nacionais para os cursos de graduação em Educação Física, em nível superior de graduação plena. Brasília, 2004. Disponível em: http://portal.mec.gov.br/cne/arquivos/pdf/2007/pces058_04.pdf. Acesso em: 27 out. 2013. 
BRASIL. Conselho Nacional de Educação. Parecer n. ${ }^{\circ}$ CNE/CP 28/2001. Estabelece a duração e carga horária dos cursos de Formação de Professores da Educação Básica, em nível superior, curso de licenciatura, de graduação plena. Brasília, 02 de outubro de 2001.

CAILLOIS, Roger. Os Jogos e os Homens: a máscara e a vertigem. (tradução de José Garcês Palha). Lisboa: Cotovia, 1990.

COLETIVO DE AUTORES. Metodologia do ensino da Educação Física. São Paulo: Cortez, 2012.

DARIDO, Suraya Cristina; RANGEL, Irene Conceição A. Educação Física na escola: implicações para a prática pedagógica. Rio de Janeiro: Guanabara Koogan, 2005.

DECIAN, Marluce R; MARIN, Elizara C. O jogo como conteúdo da educação física escolar no ensino médio: análise a partir dos referenciais curriculares dos estados brasileiros. Trabalho de Conclusão de Curso de Licenciatura em Educação Física pela Universidade Federal de Santa Maria. Santa Maria (RS), 2011.

DIETRICH, Knut; DÜRRWACHTER, Gerhard; SCAHLLER, Hans-Jurgen. Os grandes jogos: metodologia e prática. (tradução de Renate Sindermann). Rio de Janeiro: Ao Livro Técnico, 1984.

ELKONIN, Daniel B. Psicologia do jogo. (tradução de Álvaro Cabral). São Paulo: Martins Fontes, 1998.

FARIA JUNIOR, Alfredo G. de. A reinserção dos jogos populares nos programas escolares. Revista Motrivivência. Florianópolis, Ano VIII, n.9, p.44-65, 1996.

FRIGOTTO, G. O enfoque da dialética materialista histórica na pesquisa educacional, p.7090. In: FAZENDA, I (org). Metodologia da pesquisa educacional. 11 ed. São Paulo, Cortez, 2008.

FRIZZO, G. O trabalho pedagógico como referência para a pesquisa em Educação Física. Revista Pensar a Prática, 11/2: 159-167, maio/ago. 2008

FURG. Curso de Licenciatura em Educação Física. Projeto Político Pedagógico do Curso de Licenciatura em Educação Física. Rio Grande (RS), 2005.

GIROUX, Henry. Teoria Crítica e Resistência em Educação: para além das teorias da reprodução. (tradução de Ângela M. B. Biaggio). Petrópolis (RJ): Vozes, 1986.

HUIZINGA, Johan. Homo ludens: o jogo como elemento da cultura. (tradução de João Paulo Monteiro [1971]). São Paulo: Perspectiva, 1980.

KISCHIMOTO, Tizuko M. Jogos tradicionais infantis: o jogo, a criança e a educação. Petrópolis (RJ): Vozes, 1993. 
LAVEGA BURGUÉS, Pere et al. Os jogos tradicionais no mundo: associações e possibilidades. Licere, Belo Horizonte, v.14, n.2, jun/2011.

MASCHIO, Vanderléia; RIBAS, João Francisco Magno. El juego como contenido escolar en el enfoque crítico-superador. Revista Pedagógica ADAL. Madri, v.11, n.19, p.30-38, dez. 2009. Disponível em: www.apefadal.es. Acesso em: 10 de maio de 2013.

MAY, Tim. Teoria social e pesquisa social. In: MAY, Tim. Pesquisa Social: questões, métodos e processos. 3. Ed. Porto Alegre: Artmed, 2004.

MELO, Rogério Zaim. Educação Física na escola: conteúdos adequados ao $2^{\circ}$ grau. Trabalho de Conclusão de Curso de Graduação em Educação Física pelo Instituto de Biociências, Universidade Estadual Paulista. Rio Claro, 1997.

MICHELOTTI, Daniele de Vargas; SOUZA, Maristela da Silva. Análise do conhecimento teórico-metodológico dos professores em Educação Física do CEFD/UFSM em relação a sua prática pedagógica. Movimento, Porto Alegre, v.14, n. ${ }^{\circ} 02$, p.63-82, maio/agosto de 2008.

NEIRA, Marcos Garcia. Em defesa do jogo como conteúdo cultural no currículo da Educação Física. Revista Mackenzie de Educação Física e Esporte, v.8, n.2, p.25-41, São Paulo, 2009.

NOGUEIRA, Quéfren Weld Cardozo. Educação Física, jogo e cultura. Cadernos de Educação: FaE/PPGE/UFPel. Pelotas, n.29, p.119-134, jul/dez., 2007.

PIMENTA, Selma Garrido. O estágio na formação de professores: unidade teoria e prática? 5. Ed. São Paulo: Cortez, 2002.

RANGEL, Irene Conceição Andrade; DARIDO, Suraya Cristina. Jogos e Brincadeiras, p.155174. In: S. C. DARIDO e I. C. A. RANGEL (Orgs.). Educação Física na escola: implicações para a prática pedagógica. Rio de Janeiro: Guanabara Koogan, 2008.

SALGADO, Maria Umbelina Caiafa. Um olhar inicial sobre a formação de professores em serviço. In: VÁRIOS AUTORES. Um Olhar sobre a Escola. Série de Estudos para Educação a Distância. Brasília: MEC/SEED, 2000.

SANTOMÉ, Jurjo Torres. As Culturas Negadas e Silenciadas no Currículo. In: SILVA, Tomaz Tadeu da (Org.). Alienígenas na Sala de Aula: uma introdução aos estudos culturais em educação. Petrópolis (RJ): Vozes, 1995.

SILVA, Tomaz Tadeu da. O currículo como fetiche: a poética e a política do texto curricular. Belo Horizonte: Autêntica, 2006.

TRIVIÑOS, Augusto Nibaldo Silva. Introdução à pesquisa em ciências sociais: a pesquisa qualitativa em educação. São Paulo, Atlas, 1987. 
UFPEL. Escola Superior de Educação Física. Colegiado de Curso de Graduação. Projeto Pedagógico do Curso de Licenciatura em Educação Física. Pelotas (RS), 2010.

UFRGS. Escola de Educação Física. Comissão de Graduação em Educação Física. Projeto Pedagógico do Curso Educação Física - Habilitação Licenciatura. Porto Alegre, 2012.

UFSM. Centro de Educação Física e Desportos. Projeto Pedagógico do Curso de Educação Física Licenciatura Plena. Santa Maria (RS), 2005.

UNIPAMPA. Projeto Pedagógico do curso de Licenciatura em Educação Física. Uruguaiana (RS), 2012.

VEIGA, Ilma Passos Alencastro. Docentes para a Educação Superior: Processos Formativos. Campinas, SP: Papirus, 2010.

VOLPATO, Gildo. Jogo e brinquedo: reflexões a partir da teoria crítica. Educação \& Sociedade, v.23, n.81, p.217-226, Campinas, 2002.

Recebido em: 24/07/2014

Revisado em: 03/11/2014

Aprovado em: 18/11/2014

Endereço para correspondência:

marlucedecian@gmail.com

Marluce Raquel Decian

Universidade Federal de Santa Maria.

Avenida Roraima s/n

camobi

97119-900 - Santa Maria, RS - Brasil 